\title{
Study on the Relationship between Fracture Morphology and Splitting Strength of Granite Based on Fabric Distribution
}

\author{
GuangSheng Du $\mathbb{D}^{1},{ }^{1}$ ShiJiang Chen $\mathbb{D}^{1},{ }^{1}$ Xiaoyi Chen $\mathbb{D}^{\mathbb{D}},{ }^{1}$ Yunfeng Gao, ${ }^{2}$ and Hailong Wu ${ }^{2}$ \\ ${ }^{1}$ College of Mining and Coal, Inner Mongolia University of Science and Technology, Baotou, 014010 Inner Mongolia, China \\ ${ }^{2}$ Wulat Front Banner Yuanda Business Company with Limited Liability, China \\ Correspondence should be addressed to ShiJiang Chen; chenshijiang_2003@163.com
}

Received 2 June 2021; Accepted 16 July 2021; Published 2 August 2021

Academic Editor: Haojie Lian

Copyright (c) 2021 GuangSheng Du et al. This is an open access article distributed under the Creative Commons Attribution License, which permits unrestricted use, distribution, and reproduction in any medium, provided the original work is properly cited.

\begin{abstract}
Because of the requirement of the mechanical properties of the damaged surrounding granite rock and the existence of the fracture water in hydraulic fracturing engineering, the strength of granite is related to the fabric, and the roughness of the section is also related to the liquid flow rate, a method of roughly determining the strength of the specimen by observing the failure mode of rock is needed. Considering that the physical and mechanical properties of granite are obviously affected by the fabric, the discrete element numerical simulation method was used to reconstruct the granite fabric based on the spatial correlation function to simulate the splitting experiment to investigate the failure mode of the specimen. The relationship between strength, the fractal value of cross-section, and the fabric was analyzed, which was verified through experiment. The results show that (1) the Voronoi GBM model with spatial correlation function of the discrete element can effectively simulate the controllable granite fabric and carry out micromechanical analysis. (2) The strength of the granite specimen and the fractal value of the cross-section have an obvious linear relationship with the fabric; besides, there is also a certain linear relationship between the strength of the specimen and the fractal value, which is influenced by granite fabric. (3) The predicted strength of the specimen according to the fractal value of the section is in good agreement with the actual strength with the error rate of $30 \%$. In a word, this method can predict the strength of the specimen through the failure section and analyze the hydraulic fracture section and water pressure.
\end{abstract}

\section{Introduction}

During the hot dry rock mining, because surrounding rocks are mainly composed of granite, the main construction method is hydraulic fracturing; the hydraulic pressure strength and the shape of water fracture are the most important aspects to be focused [1-3]. For multicomponent crystalline rocks such as granite, the strength characteristic and fracture distribution are related to the internal crystal fabric. Therefore, an interactive relationship can be established to evaluate the hydraulic fracturing effect and water fracture development under different water pressures. Moreover, the strength characteristics are required by hydraulic fracturing [4-11], but it is difficult to carry out the test on-site; therefore, there is a certain engineering significance to establish a model for predicting the strength of the rock through the preliminary detection of the failure morphology of the rock so as to delimit the range of water pressure.

Previous research found that the root cause of the macrofailure of rock is the development and expansion of internal microcracks. Therefore, it is more suitable to analyze the failure mechanism of granite rock from the microperspective, and it is found that the mineral content and distribution have a great impact on its strength to some extent [12-16]. As shown in Figure 1, there are three kinds of microcracks formed in the process of failure, including intergranular cracks between different components, intergranular cracks between the same component, and cracks through the crystal. Obviously, they are greatly related to the mineral content, distribution pattern, and crystal interface. Some researchers 


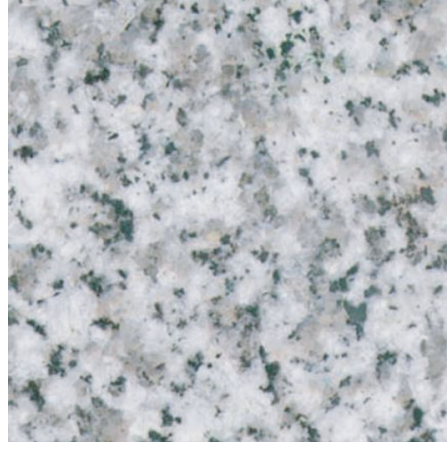

(a)

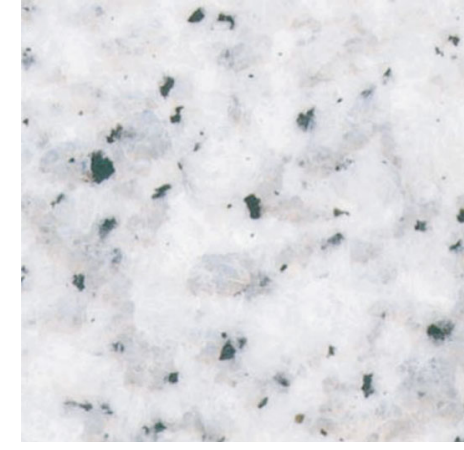

(b)

FIGURE 1: Comparison of granites with different fabrics with length and width of $30 \mathrm{~mm}$ [16].

found that the mineral content and distribution also had a significant impact on its morphology after failure [17-21], as shown in Figure 2.

According to the study mentioned above, it can be found that the characteristics of granite structure have a certain influence on the strength and failure form of the specimen. On the one hand, it is necessary to define a parameter that can effectively represent the shape of granite after failure. In fact, rock failure generally presents tensile shear failure, which is the most important failure form. Xie and Wang [22] put forward a fractal theory to describe rock fractures, and it can effectively quantify the damage of rock. Scholars have done much research on rock structure and fracture [23-26]; Chen et al. [27] described the rock surface roughness using the fractal method. On the other hand, for granite with different mineral contents and distributions, it is generally difficult to control its structure characteristic. So, the numerical simulation method is used in the study [28-33]. Some scholars have adopted the finite element method to construct the model, but there are some defects in reflecting the rock failure form. The discrete element numerical model method is used to reconstruct the mesoscopic rock structure [34-37]. Considering the distribution of minerals and anisotropy in granite, some scholars have considered homogenization, Weibull strength distribution, digital image restoration, and spatial correlation distribution [38-45]; it is difficult to control the randomness of homogeneous material modelling and Weibull function distribution modelling accurately. The digital image reconstruction method has high accuracy in modelling, but the workload is huge and still affected by the original rock distribution. The construction method of the digital function model represented by the spatial correlation function has the advantage of a highly quantitative model. In addition, the GBM model and structure model with Voronoi were proposed to take the crystal distribution into account [46-49]; they can effectively construct the crystal structure inside granite and make the failure effect consistent with the actual situation.

In this study, the spatial correlation function image Voronoi GBM modelling method is used to build the numerical model of granite rock with different mineral distributions and different component contents. Because the rock failure is mostly tensile shear failure, and the complete section is easy
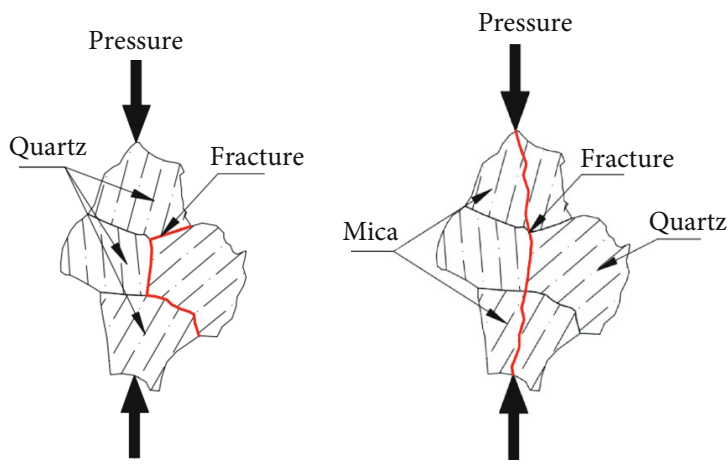

Figure 2: Development of granite fractures under different fabric conditions [19].

to be formed by splitting, the Brazilian splitting test is carried out on the numerical model, and the microcracks of the section are obtained, and then, the fractal calculation is carried out on this section. The correlation analysis of the results is carried out to establish a model for estimating the strength of the specimen with the section shape of the specimen.

\section{Construction of Granite Model}

In this study, particle flow code element numerical simulation software (PFC) is used for model construction and research; it is necessary to calibrate the corresponding parameter. Firstly, the vector models of different fabrics in granite are constructed by digital image technology. Then, the crystal structure is constructed through the Voronoi GBM model. Finally, the actual physical tests are carried out to match the strength.

\subsection{Vectorization of Different Fabric Distributions}

(1) The same parameters of a digital camera are set to obtain the information of granite surface and adjust it

(2) The recorded image is processed in MATLAB software. Firstly, the grey level processing is carried out to make the image into 0-255 different grey levels. Then, the grey value of $0-96$ is used for mica, 96195 is used for quartz, and 196-255 is for feldspar. 
Finally, the images with three textures are obtained by median denoising

(3) After median denoising, the edge image is imported into $\mathrm{R} 2 \mathrm{~V}$ for vectorization to form the recognized vector boundary model

The numerical image processing and components are shown in Figure 3.

2.2. Numerical Model of the Internal Structure of Granite. According to many experimental results, it can be known that different minerals in granite will form their own crystallization during diagenesis; in order to ensure the accuracy of the model, Potyondy [50] proposed the GBM equivalent crystal model, which is used to construct the internal crystal structure of granite. At the same time, in order to improve the controllability of the crystal, the Voronoi polygon is used to construct the crystal grid, whose strength is set to be $40 \%$ of its mineral strength. The process is shown in Figure 4.

(1) Import the vector structure into Rhinoceros software and adjust the orientation

(2) The total number of crystals generated in different mineral areas is determined by crystal size

(3) The generated crystal structure network is imported into PFC, and different models and parameters are set

2.3. Parameter Calibration of Numerical Model. In the PFC model, the parallel bond model was adopted, which can define the bond component and transfer the force between particles. When the ultimate strength of the bond component is reached, it will fail, and the model changes into a linear contact model. Then, the vector boundary of the image of the granite specimen is imported into PFC software to construct the model reflecting the original rock fabric characteristics. Referring to the previous calibration of the microparameter of granite [51-59], combined with some physical and mechanical parameters measured in this test, the parameters of this model were determined. After repeated calibration, the stress curve of the numerical test is almost consistent with the indoor test, as shown in Figure 5. The calibration results of mesoscopic parameters are shown in Tables 1 and 2 .

\section{The Numerical Simulation of Granite with Different Fabrics}

It is difficult to obtain the samples with the controllable component distribution and mineral content in the actual test, but the granite surface with different component distributions and mineral contents controlled by parameters can be effectively reconstructed by using the spatial correlation coefficient. Furthermore, the splitting test, which is easy to obtain the section morphology, was carried out.

3.1. Construction of Granite Surface with Different Fabrics. In the process of diagenesis, the components of each mineral are

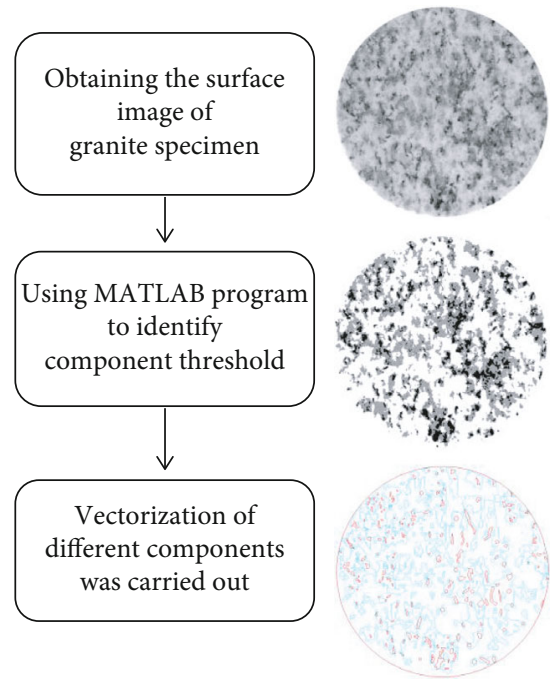

FIgURe 3: Acquisition process of the component position structure of the test piece.

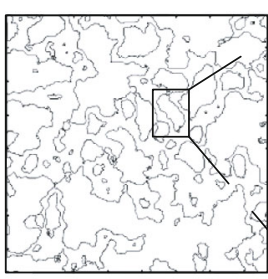

Vector model

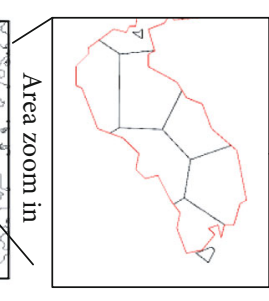

Crystal structure division

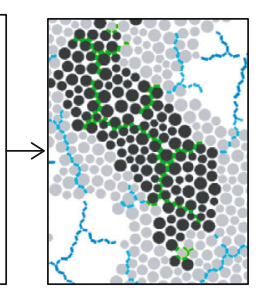

Import PFC model
Figure 4: GBM-Voronoi crystal structure construction process.

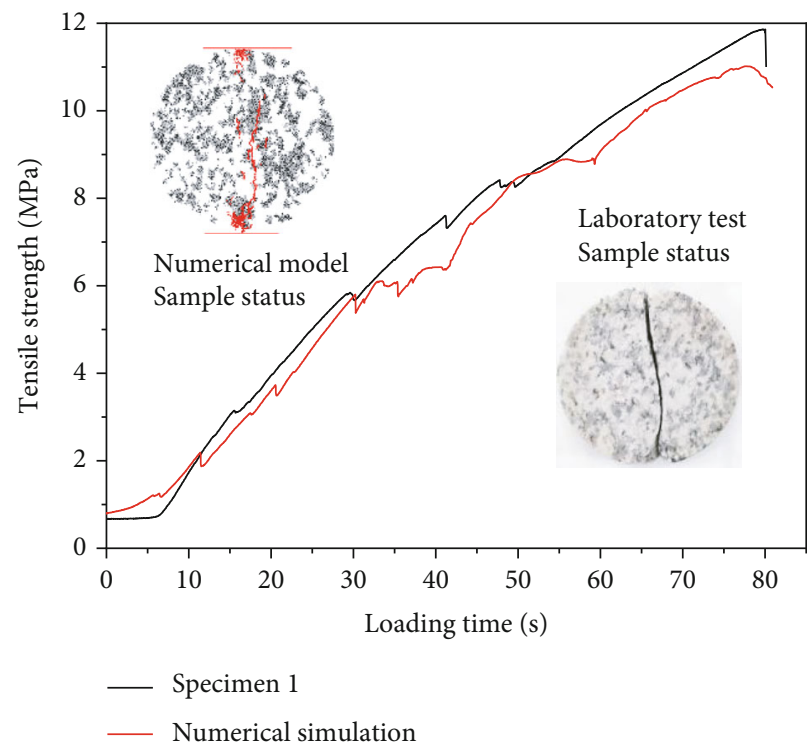

FIgURE 5: Matching curve of the numerical model and indoor test parameters. 
TABle 1: Particle mesoscopic parameters.

\begin{tabular}{lccc}
\hline Component parameters & \multicolumn{3}{c}{ Mineral } \\
& Feldspar & Quartz & Mica \\
\hline Minimum particle size $(\mathrm{mm})$ & 0.15 & 0.15 & 0.15 \\
Particle size ratio & 1.60 & 1.60 & 1.60 \\
Density $\left(\mathrm{kg} / \mathrm{m}^{3}\right)$ & 2750 & 3100 & 2650 \\
Particle modulus $(\mathrm{GPa})$ & 20 & 40 & 10 \\
Normal/tangential stiffness ratio & 2.5 & 2 & 4 \\
Friction coefficient & 0.75 & 0.80 & 0.25 \\
Porosity (\%) & & 0.954 & \\
\hline
\end{tabular}

not random but have certain correlation characteristics; the mineral distribution in a certain area has specific aggregation, and different minerals maintain certain differentiation. Because of the different mechanical properties of minerals, it has an important influence on the fracture development of rock. In this paper, the spatial correlation function is introduced to generate rock images with different fabric characteristics by changing the correlation parameters.

(1) A two-dimensional random array $A$ is established in MATLAB; the values of " $a_{i, j}$ " in the array are evenly distributed in (0-1). In order to calculate the aggregation superposition, the elements in matrix $A$ are binarized. When $0<a_{i, j}<0.5, a_{i, j}=-1$; when $0.5<$ $a_{i, j}<1, a_{i, j}=+1$

(2) In order to generate the rock image with obvious characteristics of mineral fabric aggregation, it is necessary to process the random image of array $A$ by introducing the spatial correlation function to transform it. The spatial correlation function is shown in formula (1), and the superposition method is shown in formula (2). Then, array $B$ is obtained, and rock images with obvious mineral fabric aggregation characteristics are generated. In Equation (1), parameter $L$ controls the degree of fabric accumulation of rocks and minerals. Array $B$ is the rock image at $L=6$

$$
f(d)=e^{-d / L}
$$

where $L$ is the spatial correlation length and $D$ is the effective distance between two element points.

$$
b i, j=\sum_{p=-n}^{n} \sum_{q=-n}^{n} a i+p, j+q f(d(p, q))
$$

(3) The solved array $B$ is converted into a matrix with a numerical range of 0-255. At this time, the numerical range of the matrix is consistent with the grey value of the image. Different thresholds are selected for different component contents using the grey value component partition method. Figure 6 is the distribution map of three different components after greyscale division
3.2. Model Characteristics of Granite with Different Fabrics. During the formation of rock crystallization, if the spatial correlation of different components (i.e., mineral accumulation) is only considered, the spatial correlation length segment should be selected as $L=2,4,6,8,10$ and mica content $x=0.1$. At this time, the calculation results of different spatial correlation lengths are shown in Figure 7. Given the content of mica in low-strength minerals, which has an obvious influence on the mechanical properties of the specimen, the mesostructure characterization of its spatial correlation is considered when the content of the component is different. Taking the space-related length $L=6$ as an example, the mica content $x=0.1,0.15,0.2,0.25$, and 0.3 are obtained. The calculation results of different mineral composition contents are shown in Figure 7.

3.3. Numerical Model Results. The images of different structures generated above were imported into the PFC to build the corresponding numerical model. The Brazilian splitting test method was used to load the model, and the peak strength of the final specimen is shown in Table 3.

\section{Fractal Calculation of Granite with Different Fabric Sections}

Through the processing above, the splitting strength of different fabric granite and the fracture distribution can be observed and recorded. In actual engineering, the information of the section is relatively easy to obtain, and it is a key to conduct a deeper study of granite. In recent years, fractal dimension has been widely used to describe rough surface because of its quantitative advantage and accuracy in describing fracture structure. In this study, the fractal dimension is selected to quantitatively describe the failure section.

4.1. Fractal Principle and Process. Fractal dimension is a method that can describe the complexity of the surface. In this experiment, a simple and classic box algorithm in a fractal is used, in which the image is divided into $2 n$ $(n=1,2,3 \cdots)$ different scales and the lattice of the pixels is counted. Equation (3) is used for calculation and fitting to obtain the final fractal dimension $D$. Figure 8 shows the fractal calculation results of $L=6, x=0.1$ fracture.

$$
D=-\lim \frac{\lg N(L)}{\lg L},
$$

where $D$ is the box-counting dimension, $N(L)$ is the number of grids of the fractal body covered when the grid-scale is $L$, and $L$ is the grid scale.

The fractal process is as follows:

(1) At the end of the test, the image of the fracture point of the numerical specimen is derived

(2) The image is adjusted to $2^{n}$ pixels so as to facilitate the next fractal calculation

(3) The processed image is imported into MATLAB for further image contour extraction and grey denoising 
TABLE 2: Contact micromechanical parameters.

\begin{tabular}{lcccccc}
\hline Parameter & & & Mineral composition & \\
Feldspar & Quartz & Mica & Feldspar texture & Quartz texture & Mica texture \\
\hline Normal/tangential stiffness ratio & 1.5 & 1.5 & 2.5 & 1.5 & 1.5 & 2.5 \\
Bond modulus $(\mathrm{GPa})$ & 45 & 61 & 20 & 36 & 48.8 & 16 \\
Tensile force $(\mathrm{MPa})$ & 46.2 & 58.2 & 23.1 & 18.4 & 23.3 & 3.24 \\
Cohesion $(\mathrm{MPa})$ & 83.0 & 90.1 & 45.1 & 33.2 & 25 & 18.0 \\
Friction angle $\left(^{\circ}\right)$ & 23 & 25 & 27 & 23 & 27 \\
\hline
\end{tabular}

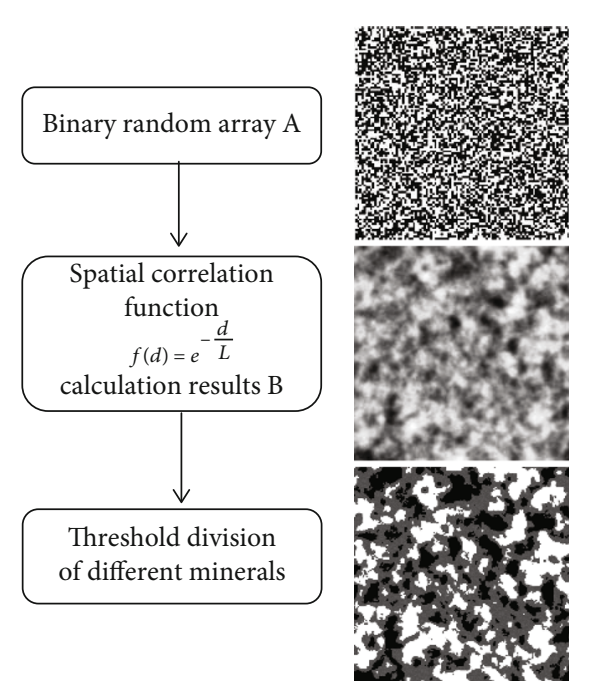

FIGURE 6: Numerical realization of rock fabric image.

(4) Finally, the box dimension algorithm programmed by MATLAB is used to divide the recognition domain of the image and fit the final fractal result $D$

4.2. Fractal Calculation Test Results. After the experiment, the image of the fracture is extracted, as shown in Figure 5, the fracture profile of the specimen. Considering the randomness of the model and fracture, specimens with the different number of fractures is tested. The purpose of this experiment is to investigate the variation of the fracture with the composition changing and to unify the treatment of fractures, which is done by counting the fractal results of 1000 fractures. The specific method calculates the fractal of the total fracture image and then brings the $D_{c}=D_{\text {initial }} \times$ $(N / 1000)$ value, where $n$ is the total number of counted fractures. The stable fractal results of 1000 fractures can be obtained, which can represent the relative complexity of the fracture section, as shown in Table. 4.

\section{Numerical Experiments and Fractal Analysis}

5.1. Analysis of Numerical Test Results. In this experiment, the samples with different mineral aggregations, i.e., spatial correlation coefficient $L=2,4,6,8,10$, were constructed; besides, each mineral aggregation was also constructed with different mica content, i.e., $x=10 \%, 15 \%, 20 \%, 25 \%, 30 \%$. In order to improve the accuracy and generality of the test, five groups of tests were carried out for every specimen, and the test results were averaged. According to the numerical test results, it can be indicated that there is a certain relationship between the distribution of different fabrics and its strength, which is fitted by the Pearson correlation coefficient, as shown in Formula (4).

$$
\operatorname{Correl}(X, Y)=\frac{\sum(x-\bar{x})(y-\bar{y})}{\sqrt{\sum(x-\bar{x})^{2}(y-\bar{y})^{2}}} .
$$

While considering the influence of the component content, the correlation coefficients of strength and mica content are set as $-0.9843,-0.98295,-0.8239,-0.7052$, and -0.8049 when $L=2,4,6,8$, and 10 , respectively. It can be seen that there is a strong negative correlation between the strength and mica content regardless of the component distribution; at the same time, as the $L$ value increases, the correlation between strength and mica content decreases. It is observed that as the degree of polymerization of components increases, the homogeneity of the specimens decreases, making the strength fluctuate. According to the linear fitting analysis based on the strong correlation, the linear relationship between the strength of five groups of specimens and the mica content can be obtained, as shown in Figure 9(a). It can be seen that except for $L=8$, the $R^{2}$ of the fitting curve for other $L$ values is relatively high and maintain a high value, suggesting that there is a very strong linear relationship between the component content and the strength of the granite samples.

While considering the effect of component distribution, the correlation coefficients between $L$ and strength are $-0.9365,-0.9755,-0.9093,-0.9190$, and -0.9557 when the mica content is $10 \%, 15 \%, 20 \%, 25 \%$, and $30 \%$, respectively. The results show that there is a strong negative correlation between the strength of the specimen and the polymerization of its components; the strength of the specimen decreases with the increase of the aggregation degree of the components. At the same time, based on the strong correlation, the linear fitting between the strength of the specimen and its polymerization is carried out, and the results are shown in Figure 9(b). The results show that there is an obvious linear relationship between the strength of the specimen and the degree of polymerization.

5.2. Fracture Fractal Analysis Results. In this experiment, the fractal of the crack image is calculated after the stress dropping; then, the crack is processed to show the state of its section. In order to explore the relationship between the 


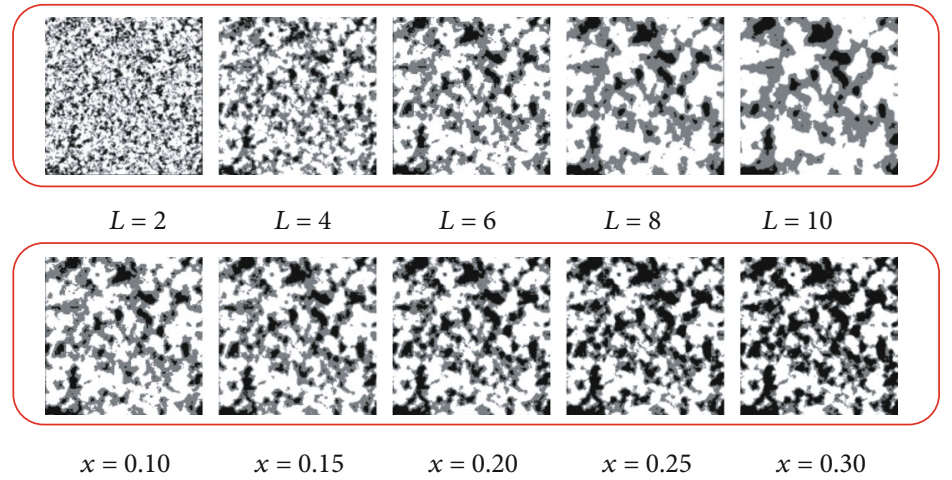

FIgURE 7: Image of different fabric granite specimens.

TABLE 3: Results of splitting strength of specimens with different fabrics.

\begin{tabular}{lccccc}
\hline Components distribution & \multicolumn{5}{c}{ Tensile strength (MPa) } \\
Mica content & $L=2$ & $L=4$ & $L=6$ & $L=8$ & $L=10$ \\
\hline$x=0.10$ & 17.07 & 15.28 & 13.67 & 12.71 & 11.94 \\
$x=0.15$ & 13.45 & 12.15 & 10.74 & 10.25 & 9.46 \\
$x=0.20$ & 10.39 & 11.28 & 9.73 & 9.78 & 8.39 \\
$x=0.25$ & 9.61 & 9.76 & 9.93 & 9.51 & 7.77 \\
$x=0.35$ & 9.13 & 8.37 & 8.51 & 8.59 & 6.97 \\
\hline
\end{tabular}

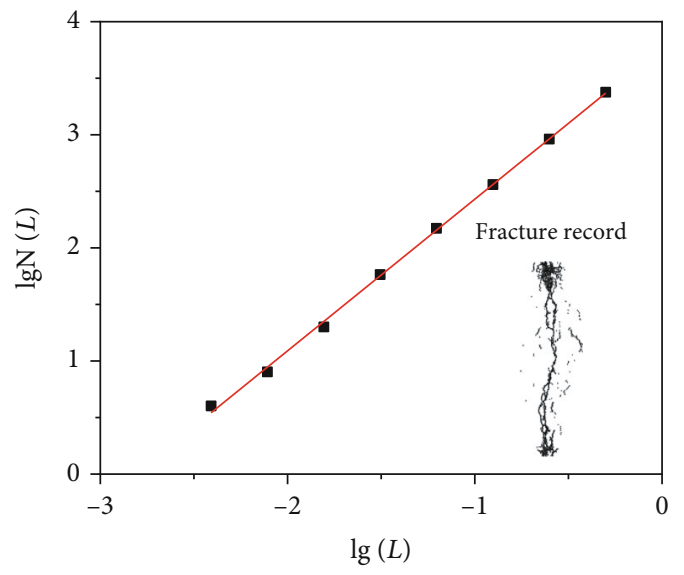

- Data point

- Fit line $y=1.341 x+3.7713 R^{2}=0.9988$

$D=1.341$

FIGURE 8: Calculation results of fractal dimension of $L=6$ specimen.

complexity of the section and the internal fabric of the rock, the same correlation algorithm is used for the correlation test.

While considering the effect of the component content, under the condition of different polymerization degrees, The correlation coefficients of mineral aggregation degree and fractal dimension of fracture surface are -0.9674 , - 0.9326, - 0.8295, $-0.9477,-0.9962$, and -0.9346 for $L=2$, $4,6,8$, and 10 , respectively. The results show that the fractal dimension of the fracture is strongly correlated with the mica content under conditions of different mineral polymerizations, and the correlation is as high as -0.9962 for $L=8$, as shown in Figure 10(a). Obviously, there is a strong positive linear relationship between the fractal value of cross-section and the mica content of the specimen.

While considering the effect of component distribution, the correlation coefficients are $0.6819,0.6452,0.8536$, 0.9621 , and 0.8773 when the mica content $x=10 \%, 15 \%$, $20 \%, 25 \%$, and $30 \%$, respectively. It can be seen that the mineral polymerization has a certain correlation with the cross-section of the specimen, as shown in Figure 10(b). When the mica content is low, this correlation is low, which can be explained as that when the mica content is low, the specimen with a high degree of polymerization presents obvious anisotropy, affecting the fractal value of the specimen section. For a certain degree of correlation, the fractal distribution of different components in the section is fitted in Figure 10(b). Similarly, when the mica content is low, the correlation between the component distribution and the fracture section is poor, which can not be fitted by an obvious linear relationship. However, according to the observation, it can be seen that with the increase of mineral aggregation, the fracture fractal also presents an increasing trend.

5.3. Fractal Analysis of Specimen Strength and Fracture Section. It is analyzed that there is a very obvious linear relationship between the strength of the specimen and its fabric, as well as the fractal of the section and the fabric of the specimen. So, accordingly, the correlation between the strength of the specimen and the fractal of the section can be established, which is 0.45574 . The correlation between the two groups of data is low, which is corresponding to the phenomenon of poor regularity found before. In fact, the influence of component polymerization degree and mica content on fracture fractal should also be considered. When $L=2,4,6,8$, and 10 , the correlation between fractal dimension and strength is $0.9595,0.97725,0.4452,0.5345$, and 0.8211 , and the average value is 0.7475 , which is obviously higher than the simply calculated fractal value. It can be seen that there is a high correlation between the section fractal and the strength of the specimen of different component contents under the condition of different degrees of polymerization, as shown in 
TABLE 4: Fractal results of fracture numerical test section of specimens with different fabrics.

\begin{tabular}{lccccc}
\hline $\begin{array}{l}\text { Components distribution } \\
\text { Mica content }\end{array}$ & $L=2$ & $L=4$ & Section fractal dimension $D$ & $L=8$ & $L=10$ \\
\hline$x=0.10$ & 0.912315 & 0.992276 & 0.992943 & 1.060564 & 0.991415 \\
$x=0.15$ & 0.890919 & 0.894577 & 0.844273 & 0.930608 & 0.96675 \\
$x=0.20$ & 0.846622 & 0.838361 & 0.835241 & 0.906288 & 0.942929 \\
$x=0.25$ & 0.781603 & 0.819526 & 0.835196 & 0.857879 & 0.929199 \\
$x=0.35$ & 0.782504 & 0.803829 & 0.79966 & 0.826024 & 0.90456 \\
\hline
\end{tabular}

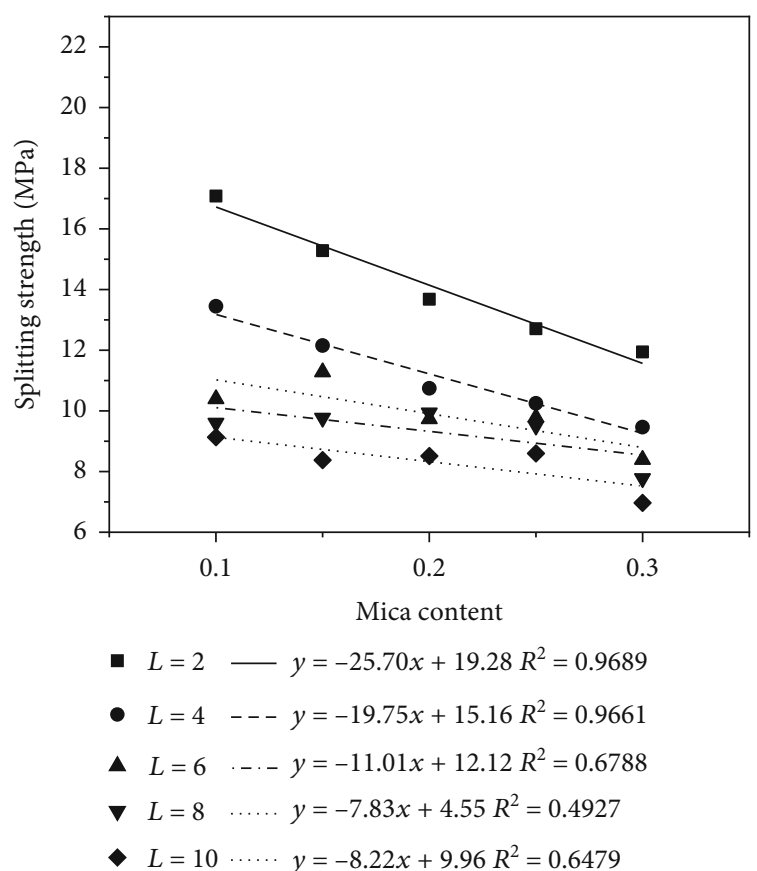

(a) Relationship between mica content and specimen strength

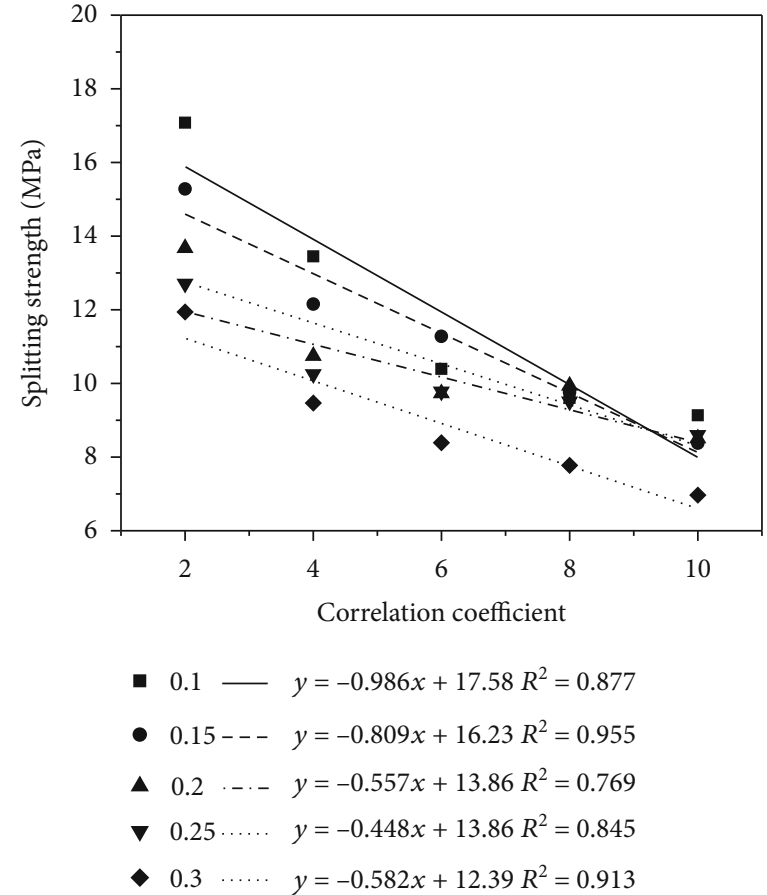

(b) Relationship between the mineral distribution and specimen strength

FIGURE 9: Relationship between different mineral fabrics and specimen strength.

Figure 11, but this correlation is slightly low when $L=6$ and 8. It is analyzed that the strength of the two groups of specimens changes greatly with the mica content, while the section fractal changes slightly with the mica content; the reason is that the failure position in the specimen is relatively uniform without obvious change. This strong correlation can be obtained by linear fitting the two groups of parameters, as shown in Figure 11. It can be seen that there is an obvious linear relationship between the strength of the specimen and its section fractal when $L=2,4,10$.

On the other hand, for mica content of $x=10 \%, 15 \%$, $20 \%, 25 \%$, and $30 \%$, the correlation between the fractal of the cross-section and the strength of the specimens is $-0.813,-0.5883,-0.5918,-0.8774$, and -0.76601 , and the average value is -0.7293 , which is higher than the fractal value. It is found that this correlation is low when $x=15 \%$ and $20 \%$, and the larger or smaller mica component content will produce relatively stable fractures. When the aggregation degree becomes large enough, the stable state of each failure will be destroyed to obtain a relatively stable fractal growth. The fitting results of the relationship between fractal and strength are shown in Figure 11; when the mica content is small, the composition of the fracture is less affected. The linear fitting results show that the fractal value of the cross-section has a linear relationship with the strength of the specimen, whose linearity is obvious at the lower or higher degree of polymerization.

Based on the above fitting curve, it can be known that the above formula can be used for low or high mica content and low or high mineral aggregation distribution.

\section{Test Verification}

By means of numerical simulation and image calculation, the relationship between the fractal dimension and the strength of the specimen under the condition of different fabrics is 

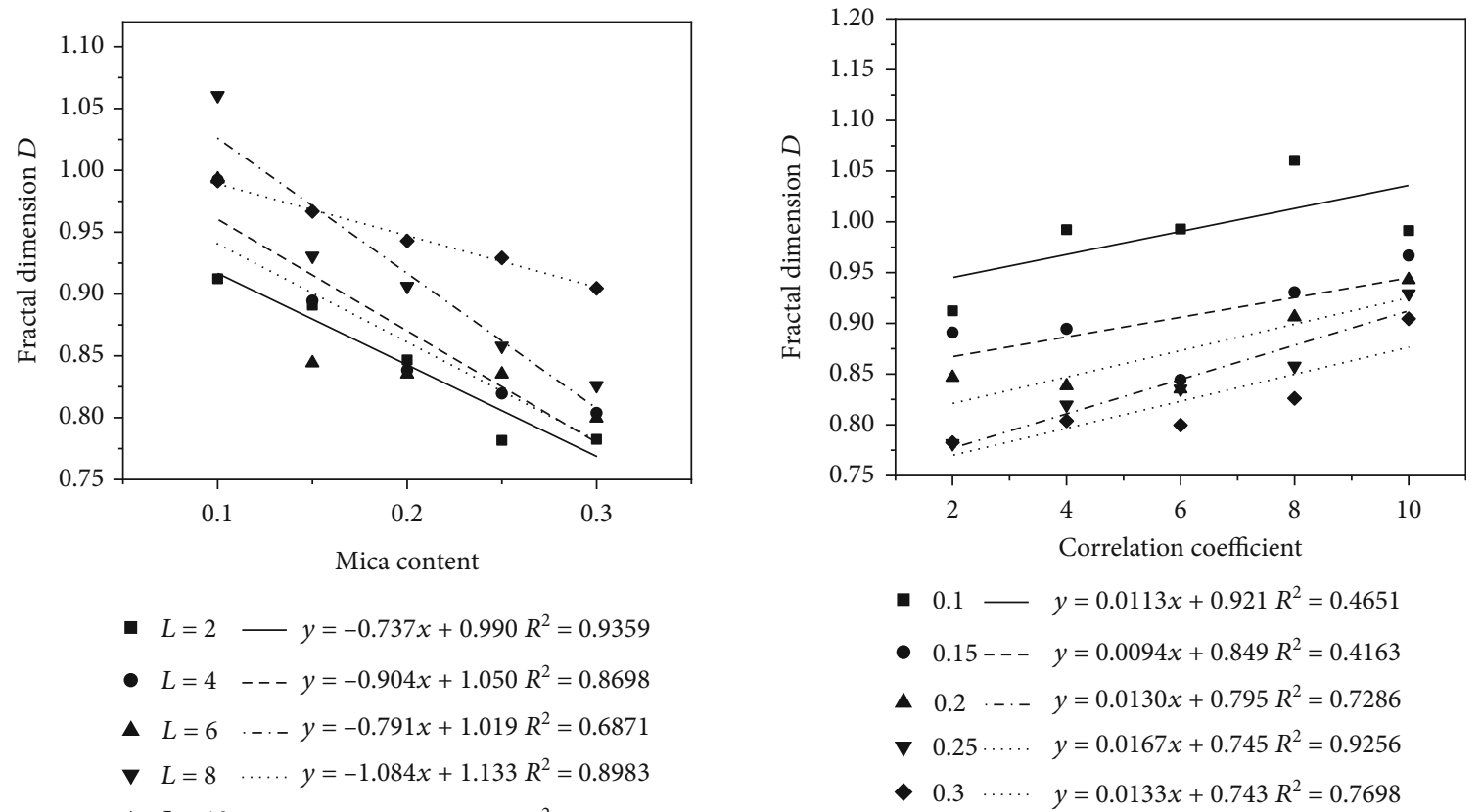

(a) Relationship between mica content and specimen strength

(b) Relationship between the mineral distribution and specimen strength

FiguRE 10: Fractal relationship between different mineral fabrics and specimen section.
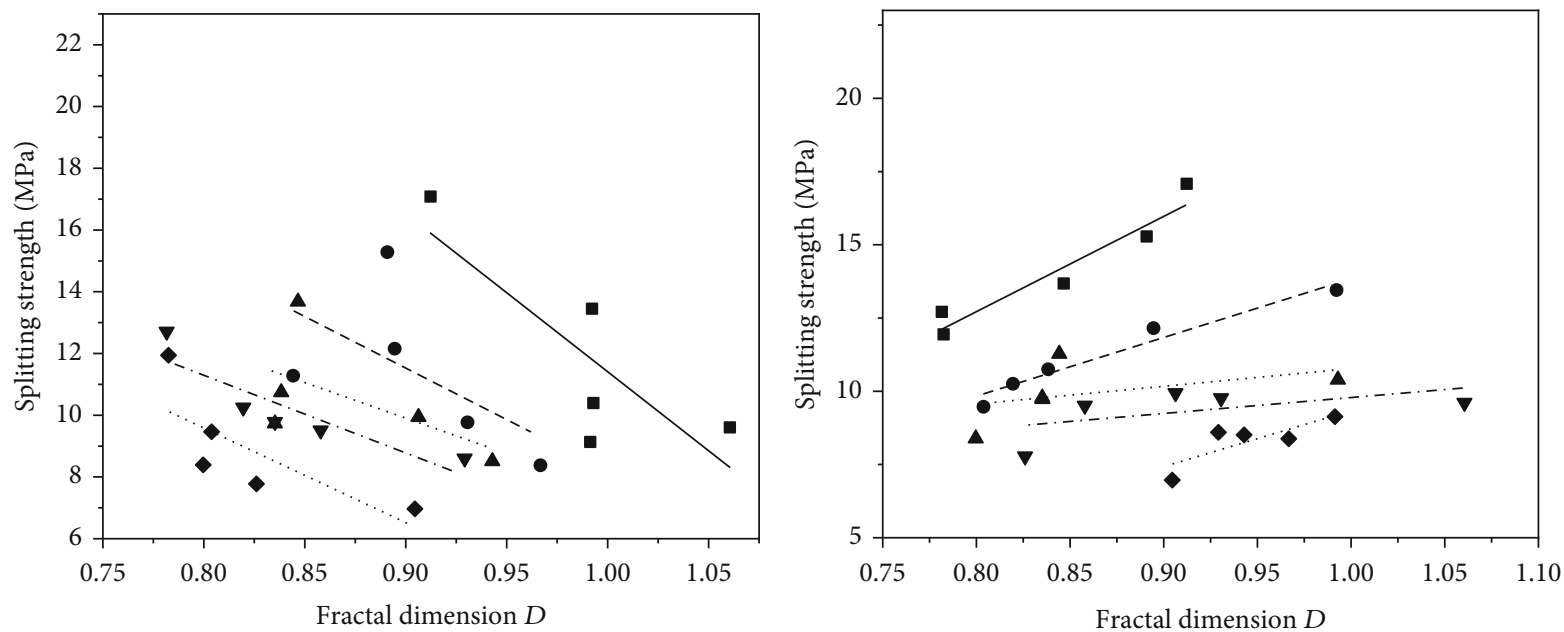

- $0.1-y=-51.59 x+63.0 R^{2}=0.6611$

- $0.15--y=-33.52 x+41.7 R^{2}=0.3461$

\ $0.2 \ldots y=-23.76 x+31.3 R^{2}=0.3503$

จ $0.25 \cdots \cdots y=-24.96 x+31.2 R^{2}=0.7875$

- $0.3 \quad \cdots . . . y=-30.73 x+34.2 R^{2}=0.5868$
- $L=2-y=32.85 x-13.5 R^{2}=0.9208$
- $L=4--y=20.25 x-6.40 R^{2}=0.9550$
\ $L=6 \quad-\quad y=6.234 x+4.54 R^{2}=0.1982$
$\boldsymbol{\nabla} L=8 \quad \ldots, y=5.193 x+4.56 R^{2}=0.2858$
- $L=10 \cdots y=19.77 x-10.4 R^{2}=0.6743$

FIGURE 11: Relationship between fracture fractal and specimen strength under different fabric parameters.

obtained. Furthermore, this relationship will be verified through the corresponding indoor test.

6.1. Indoor Splitting Test. In order to obtain a complete granite section that is the same as the numerical test above, the Brazilian splitting tensile test method recommended by the international standard is used to test the specimen. The test equipment is shown in Figure 12.

(1) The surface distribution and content of the granite slab can be observed (the content can be accurately obtained by means of threshold division of numerical 


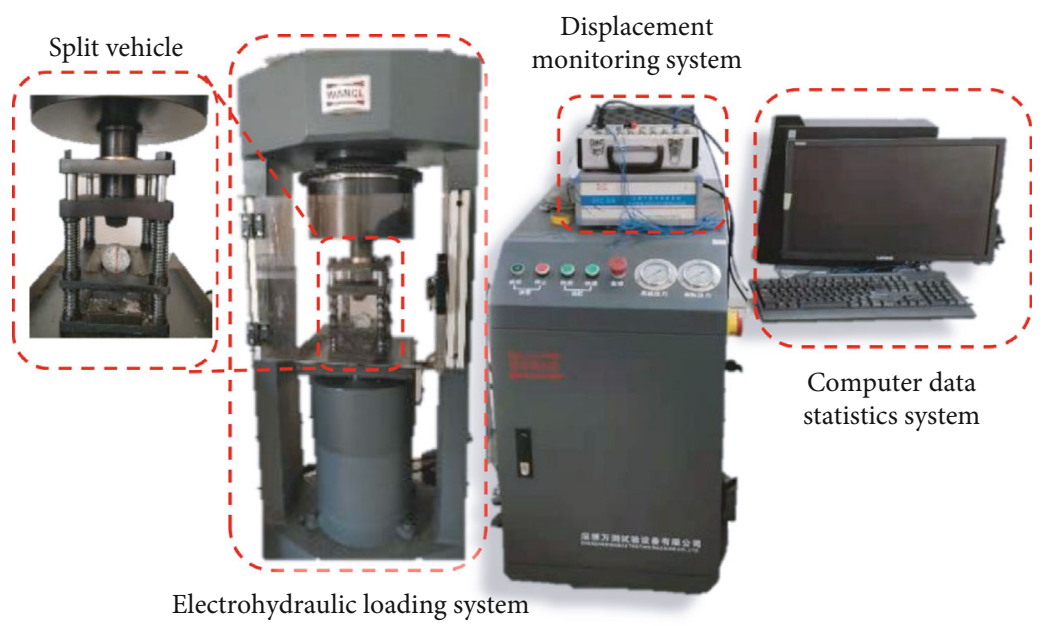

FIGURE 12: Wance electrohydraulic servo press.

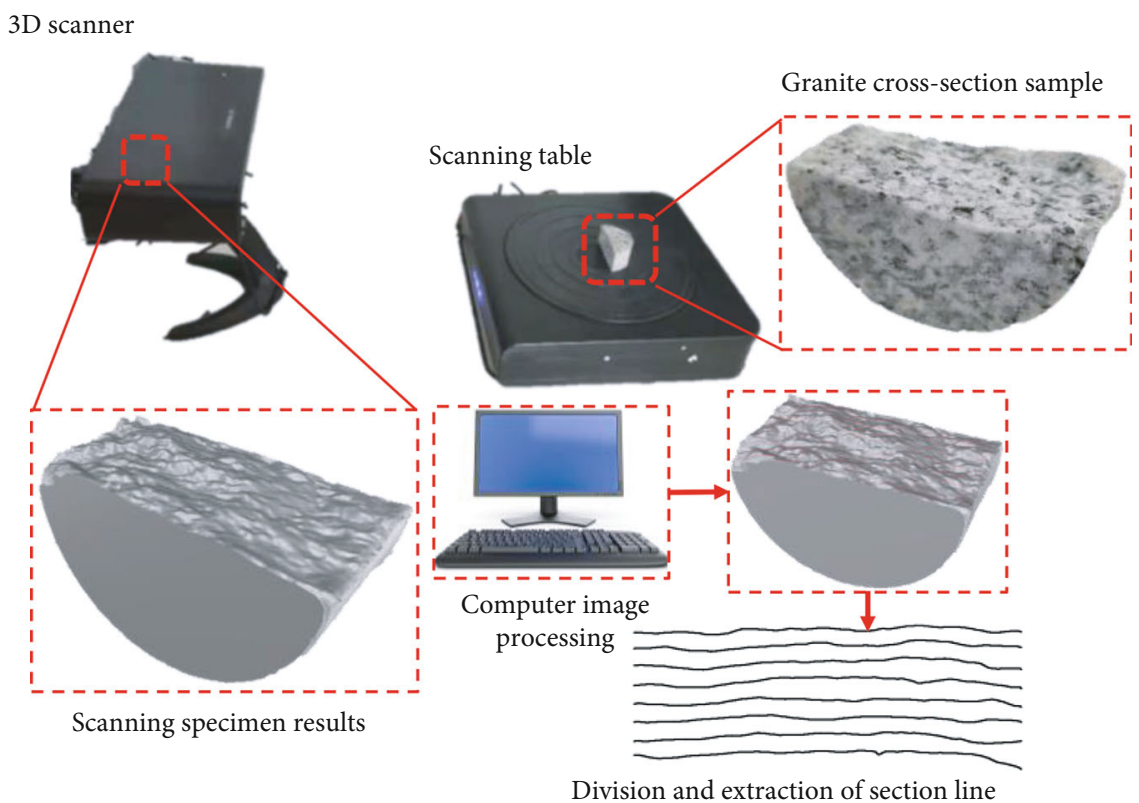

FIGURE 13: Fractal acquisition of granite specimen section.

image processing) to determine the distribution of mineral fabric

(2) The standard specimen is obtained by cutting the specimen into $\Phi 50 \mathrm{~mm} \times 25 \mathrm{~mm}$

(3) Place the test piece on the vehicle for loading. The peak load is defined as the tensile strength

6.2. Section Fractal Calculation. The fractal dimension of the section is calculated. The profile of the section can be obtained by using convenient binocular stereo image technology [60]. In this experiment, to guarantee accuracy, the Xinlin 3D laser scanner is adopted to obtain the section morphology; by slicing the 3D model, the fractal results are obtained from the section lines of several groups of sections.
Finally, the fractal results of the section are obtained by taking the average value of the results.

(1) After splitting, the specimen surface was observed, and the residual debris on the surface was removed

(2) The specimen with cross-section is scanned in three dimensions to obtain the profile information of the section

(3) The scanned specimen was imported into rhinoceros for adjustment, and its surface was segmented with equal width of $3 \mathrm{~mm}$. Finally, 8 section lines were obtained

(4) The average value of 8 section lines was calculated by fractal, as shown in Figure 13 
6.3. Validation of Results. Four groups of tests have been carried out, in which the mica content of the test piece is about $10 \%$, and the distribution of components in different aggregation areas is on the same granite slab, which can be divided into three kinds of polymerization conditions: high, medium, and low. The fractal values of the test section are 0.9512, $0.9521,0.9679$, and 1.0153 . When $x$ is $10 \%$, the fitting curve of different distributions is $y=-51.59 x+63.0$. The calculated strength values should be $13.92 \mathrm{MPa}, 13.88 \mathrm{MPa}$, 13.07 MPa, and 10.62 MPa, respectively, while the actual measured strength values are $14.53 \mathrm{MPa}, 12.67 \mathrm{MPa}$, $10.91 \mathrm{MPa}$, and $9.71 \mathrm{MPa}$, respectively. It can be seen that the numerical strength and the experimental strength have great consistency, and they all decrease with the increase of fractal value; the error ratios are $-4.19 \%, 9.55 \%, 19.79 \%$, and $9.37 \%$, respectively, and the overall fluctuation is within $30 \%$. The results show that other factors such as structural joints can lead the strength of rock samples to change, and they are not fully taken into account. It is proved that this method can predict the rock strength through the fractal and fabric of the rock section on a certain scale.

\section{Discussion}

The test results and test verification show that there is a certain linear relationship between the fractal value of the granite section and its strength under certain fabric conditions. According to the results, the component content and mineral aggregation have a strong fitting linear relationship with the strength and fractal section of the specimen. A parameter is defined to integrate the two groups of different parameters to make the strength and fractal section of the specimen show a more obvious correlation by adjusting the parameter. The corresponding formula is obtained.

\section{Conclusion}

Based on the requirements of hydraulic pressure strength and fracture analysis of the fracture water zone in hydraulic fracturing construction, considering the difference of rock component distribution and mineral content, numerical models of different fabrics are constructed to carry out the splitting test, and the fractal quantitative solution of its section is carried out.

(1) Based on the spatial correlation function and discrete element numerical simulation, the granite specimens with different fabrics can be reconstructed effectively to study further the mechanical problems combined with various monitoring methods

(2) The numerical test results show that there is an obvious linear relationship between the fabric of granite and the strength and the fractal value of the section; the strength of the specimen decreases with the increase of mica content, and the unit fractal value of the section decreases with the increase of mica content for the same polymerization degree. For the same mica content, the strength of specimens decreases with the increase of different polymerization degrees. The fractal of the fracture surface increases with the increase of mineral aggregation

(3) The results of numerical and physical tests show that when the specimen is distinguished to a certain extent; the strength of the specimen shows a linear relationship with the unit fractal value of the section under specific conditions. The strength of the specimen with the section can be roughly predicted by judging the fractal value of the section and the composition of the specimen, and the predicted value fluctuates within $30 \%$.

\section{Data Availability}

(1) The (figure) data used to support the findings of this study are included within the article. (2) The (table) data used to support the findings of this study are included within the article

\section{Conflicts of Interest}

The authors declare that they have no conflicts of interest.

\section{References}

[1] H. Zhang, Z. Wan, and D. Elsworth, "Failure behavior of hotdry-rock (HDR) in enhanced geothermal systems: macro to micro scale effects," Geofluids, vol. 2020, Article ID 8878179, 13 pages, 2020.

[2] J. Yang, H. Lian, and L. Li, "Fracturing in coals with different fluids: an experimental comparison between water, liquid $\mathrm{CO}_{2}$, and supercritical $\mathrm{CO}_{2}$," Scientific Reports, vol. 10, no. 1, p. 18681, 2020.

[3] K. M. Ajayi and S. J. Schatzel, "Transport model for shale gas well leakage through the surrounding fractured zones of a longwall mine," International Journal of Mining Science and Technology, vol. 30, no. 5, pp. 635-641, 2020.

[4] Z. Lei, Y. Zhang, Z. Hu et al., "Application of water fracturing in geothermal energy mining: insights from experimental investigations," Energies, vol. 12, no. 11, p. 2138, 2019.

[5] J. Yang, H. Lian, and V. P. Nguyen, "Study of mixed mode I/II cohesive zone models of different rank coals," Engineering Fracture Mechanics, vol. 246, 2021.

[6] J. Yang, H. Lian, and L. Li, "Investigating the effect of confining pressure on fracture toughness of $\mathrm{CO}_{2}$-saturated coals," Engineering Fracture Mechanics, vol. 242, article 107496, 2021.

[7] Z. Liu, S. Wang, H. Ye et al., "Experimental study on the effects of pre-cracks, fracturing fluid, and rock mechanical characteristics on directional hydraulic fracturing with axial precracks," Geomechanics and Geophysics for Geo-Energy and Geo-Resources, vol. 7, no. 2, pp. 7-29, 2021.

[8] Y. G. Zhang, Z. Zhang, S. Xue, R. Wang, and M. Xiao, "Stability analysis of a typical landslide mass in the Three Gorges Reservoir under varying reservoir water levels," Environmental Earth Sciences, vol. 79, no. 1, 2020.

[9] Y. G. Zhang, Y. L. Xie, Y. Zhang, J. Qiu, and S. Wu, “The adoption of deep neural network (DNN) to the prediction of soil liquefaction based on shear wave velocity," Bulletin of 
Engineering Geology and the Environment, vol. 80, no. 6, pp. 5053-5060, 2021.

[10] Z. Liu, X. Ren, X. Lin, H. Lian, L. Yang, and J. Yang, "Effects of confining stresses, pre-crack inclination angles and injection rates: observations from large-scale true triaxial and hydraulic fracturing tests in laboratory," Rock Mechanics and Rock Engineering, vol. 53, no. 4, pp. 1991-2000, 2020.

[11] Y. Nie, G. Zhang, J. Wen, S. Li, and D. Zhou, "Cyclic injection to reduce hydraulic fracture surface roughness in glutenite reservoirs," International Journal of Rock Mechanics and Mining Sciences, vol. 142, p. 104740, 2021.

[12] L. Sousa, "Petrophysical properties and durability of granites employed as building stone: a comprehensive evaluation," Bulletin of Engineering Geology and the Environment, vol. 73, no. 2, pp. 569-588, 2014.

[13] L. M. O. Sousa, "The influence of the characteristics of quartz and mineral deterioration on the strength of granitic dimensional stones," Environmental Earth Sciences, vol. 69, no. 4, pp. 1333-1346, 2013.

[14] I. Rigopoulos, B. Tsikouras, P. Pomonis, and K. Hatzipanagiotou, "Correlations between petrographic and geometrical properties of ophiolitic aggregates from Greece," Bulletin of Engineering Geology and the Environment, vol. 73, no. 1, pp. 1-12, 2014.

[15] I. Rigopoulos, B. Tsikouras, P. Pomonis, and K. Hatzipanagiotou, "Petrographic investigation of microcrack initiation in mafic ophiolitic rocks under uniaxial compression," Rock Mechanics and Rock Engineering, vol. 46, no. 5, pp. 1061-1072, 2013.

[16] Y. Nara, "Effect of anisotropy on the long-term strength of granite," Rock Mechanics and Rock Engineering, vol. 48, no. 3, pp. 959-969, 2015.

[17] S. P. Morgan, C. A. Johnson, and H. H. Einstein, "Cracking processes in Barre granite: fracture process zones and crack coalescence," International Journal of Fracture, vol. 180, no. 2, pp. 177-204, 2013.

[18] S. S. Lim, C. D. Martin, and U. Åkesson, "In-situ stress and microcracking in granite cores with depth," Engineering Geology, vol. 147-148, pp. 1-13, 2012.

[19] S. Qi, H. Lan, D. Martin, and X. Huang, "Factors controlling the difference in Brazilian and direct tensile strengths of the Lac du Bonnet granite," Rock Mechanics and Rock Engineering, vol. 53, no. 3, pp. 1005-1019, 2020.

[20] M. Sajid, J. Coggan, M. Arif, J. Andersen, and G. Rollinson, "Petrographic features as an effective indicator for the variation in strength of granites," Engineering Geology, vol. 202, pp. 44-54, 2016.

[21] W. Yin, Z. Feng, and Y. Zhao, "Effect of Grain Size on the Mechanical Behaviour of Granite Under High Temperature and Triaxial Stresses," Rock Mechanics and Rock Engineering, vol. 54, no. 2, pp. 745-758, 2021.

[22] H. Xie and J.-a. Wang, "Direct fractal measurement of fracture surfaces," International Journal of Solids and Structures, vol. 36, no. 20, pp. 3073-3084, 1999.

[23] D. Huang, X. Chang, Y. Tan, K. Fang, and Y. Yin, "From rock microstructure to macromechanical properties based on fractal dimensions," Advances in Mechanical Engineering, vol. 11, no. 3, 2019.

[24] J. Zhang, L. Yu, H. Jing, and R. Liu, "Estimating the effect of fractal dimension on representative elementary volume of randomly distributed rock fracture networks," Geofluids, vol. 2018, Article ID 7206074, 13 pages, 2018.
[25] Y. Li and R. Huang, "Relationship between joint roughness coefficient and fractal dimension of rock fracture surfaces," International Journal of Rock Mechanics and Mining Sciences, vol. 75, pp. 15-22, 2015.

[26] Z. Z. Zhang, "Fractal dimension of fracture surface in rock material after high temperature," Advances in Materials Science and Engineering, vol. 2015, Article ID 468370, 6 pages, 2015.

[27] S. J. Chen, W. C. Zhu, Q. L. Yu, and X. G. Liu, "Characterization of anisotropy of joint surface roughness and aperture by variogram approach based on digital image processing technique," Rock Mechanics and Rock Engineering, vol. 49, no. 3, pp. 855-876, 2016.

[28] M. Min, B.-S. Jiang, M.-M. Lu, J.-K. Long, and Q. Zhang, “An improved strain-softening model for Beishan granite considering the degradation of elastic modulus," Arabian Journal of Geosciences, vol. 13, no. 6, 2020.

[29] P. Li, X. Zhao, Z. Guo, and L. Ma, "Variation of strength parameters of Beishan granite under triaxial compression," Chinese Journal of Rock Mechanics and Engineering, vol. 36, no. 7, pp. 1599-1610, 2017.

[30] D. J. Xue, L. Gao, L. Lu et al., “An acoustic emission-based cluster damage model for simulating triaxial compression behaviors of granite," Rock Mechanics and Rock Engineering, vol. 53, no. 9, pp. 4201-4220, 2020.

[31] Y. G. Zhang, J. Tang, Z. Y. He, J. Tan, and C. Li, “A novel displacement prediction method using gated recurrent unit model with time series analysis in the Erdaohe landslide," Natural Hazards, vol. 105, no. 1, pp. 783-813, 2021.

[32] Y. G. Zhang and L. Yang, "A novel dynamic predictive method of water inrush from coal floor based on gated recurrent unit model," Natural Hazards, vol. 105, no. 2, pp. 2027-2043, 2021.

[33] W. Chen, H. Konietzky, C. Liu, and X. Tan, "Hydraulic fracturing simulation for heterogeneous granite by discrete element method," Computers and Geotechnics, vol. 95, pp. 115, 2018.

[34] J. Shang, "Rupture of veined granite in polyaxial compression: insights from three-dimensional discrete element method modeling," Journal of Geophysical Research: Solid Earth, vol. 125, no. 2, 2020.

[35] H. Feng, L. Tianyong, and G. Xiaoye, "Study on the macromicro failure mechanism of granite and its geometry effect under the different conditions of confining pressure by discrete element," Journal of the China Coal Society, vol. 44, no. 3, pp. 923-932, 2019.

[36] J. Hamdi, L. Scholtès, M. Souley, and M. al Heib, "Effect of discretization at laboratory and large scales during discrete element modelling of brittle failure," International Journal of Rock Mechanics and Mining Sciences, vol. 100, pp. 48-61, 2017.

[37] Z. Xuepeng, G. Wang, and J. Yujing, "Simulation research on granite compression test based on particle discrete element model," Rock and Soil Mechanics, vol. 35, Supplement 1, pp. 99-105, 2014.

[38] S. Chen, Z. Q. Yue, and L. G. Tham, "Digital image-based numerical modeling method for prediction of inhomogeneous rock failure," International Journal of Rock Mechanics and Mining Sciences, vol. 41, no. 6, pp. 939-957, 2004.

[39] C. Shi, W. Yang, J. Yang, and X. Chen, "Calibration of microscaled mechanical parameters of granite based on a bondedparticle model with 2D particle flow code," Granular Matter, vol. 21, no. 2, 2019. 
[40] G. Ma, W. Zhou, R. A. Regueiro, Q. Wang, and X. Chang, "Modeling the fragmentation of rock grains using computed tomography and combined FDEM," Powder Technology, vol. 308, pp. 388-397, 2017.

[41] T. Xinwei, Z. Yuande, and Z. Chuhan, "A mesomechanical model with spatial correlation scale character and its application," Rock and Soil Mechanics, vol. 33, no. 7, pp. 2021-2026, 2012.

[42] T. Xinwei, H. Wenmin, Z. Yuande et al., "Experimental and meso-scale numerical modeling of splitting tensile behavior of weathered granites from South China," Engineering Mechanics, vol. 34, no. 6, pp. 246-256, 2017.

[43] X. Tang, Y. Zhou, C. Zhang, and J. Shi, "Study on the heterogeneity of concrete and its failure behavior using the equivalent probabilistic model," Journal of Materials in Civil Engineering, vol. 23, no. 4, pp. 402-413, 2011.

[44] X. Tang, X.-B. Yang, and Y.-D. Zhou, “An efficient algorithm for spatially-correlated random fields generation and its applications on the two-phase material," Solid State Communications, vol. 182, pp. 30-33, 2014.

[45] D. O. Potyondy, A grain-based model for rock: approaching the true microstructure, Rock Mechanics in the Nordic Countries, Kongsberg, Norway, 2010.

[46] Z. Yu, Y. Gao, S. Wu et al., "An equivalent crystal model for mesoscopic behavior of rock," Chinese Journal of Rock Mechanics and Engineering, vol. 34, no. 6, pp. 511-519, 2014.

[47] X. F. Li, Q. B. Zhang, H. B. Li, and J. Zhao, "Grain-based discrete element method (GB-DEM) modelling of multi-scale fracturing in rocks under dynamic loading," Rock Mechanics and Rock Engineering, vol. 51, no. 12, pp. 3785-3817, 2018.

[48] Y. Lv, H. Li, X. Zhu et al., "Discrete element method simulation of random Voronoigrain-based models," Cluster Computingthe Journal Of Networks Software Tools and Applications, vol. 20, no. S1, pp. 335-345, 2018.

[49] E. Ghazvinian, M. S. Diederichs, and R. Quey, “3D random Voronoi grain-based models for simulation of brittle rock damage and fabric-guided micro-fracturing," Journal of Rock Mechanics and Geotechnical Engineering, vol. 6, no. 6, pp. 506-521, 2014.

[50] D. O. Potyondy, "A grain-based model for rock: approaching the true microstructure," in Rock Mechanics in the Nordic Countries 2010, Kongsberg, Norway, June 9-12, 2010, pp. 225-234, Norwegian Group for Rock Mechanics, 2010.

[51] H. Hofmann, T. Babadagli, J. S. Yoon, A. Zang, and G. Zimmermann, "A grain based modeling study of mineralogical factors affecting strength, elastic behavior and micro fracture development during compression tests in granites," Engineering Fracture Mechanics, vol. 147, pp. 261-275, 2015.

[52] N. Bahrani, P. K. Kaiser, and B. Valley, "Distinct element method simulation of an analogue for a highly interlocked, non-persistently jointed rockmass," International Journal of Rock Mechanics and Mining Sciences, vol. 71, pp. 117-130, 2014.

[53] X. Hu, N. Xie, Q. Zhu, L. Chen, and P. C. Li, "Modeling damage evolution in heterogeneous granite using digital imagebased grain-based model," Rock Mechanics and Rock Engineering, vol. 53, no. 11, pp. 4925-4945, 2020.

[54] T. Yin, S. Zhang, X. Li, and L. Bai, "A numerical estimate method of dynamic fracture initiation toughness of rock under high temperature," Engineering Fracture Mechanics, vol. 204, pp. 87-102, 2018.
[55] B. Shu, M. Liang, S. Zhang, and J. Dick, "Numerical modeling of the relationship between mechanical properties of granite and microparameters of the flat-joint model considering particle size distribution," Mathematical Geosciences, vol. 51, no. 3, pp. 319-336, 2019.

[56] J. Qiu, L. Luo, X. Li, D. Li, Y. Chen, and Y. Luo, "Numerical investigation on the tensile fracturing behavior of rockshotcrete interface based on discrete element method," International Journal of Mining Science and Technology, vol. 30, no. 3, pp. 293-301, 2020.

[57] H. Lin, W. H. Kang, J. Oh, I. Canbulat, and B. Hebblewhite, "Numerical simulation on borehole breakout and borehole size effect using discrete element method," International Journal of Mining Science and Technology, vol. 30, no. 5, pp. 623633, 2020.

[58] R. Abousleiman, G. Walton, and S. Sinha, "Understanding roof deformation mechanics and parametric sensitivities of coal mine entries using the discrete element method," International Journal of Mining Science and Technology, vol. 30, no. 1, pp. 123-129, 2020.

[59] G. du, S. Chen, and Z. Li, "Study on the tensile strength and crack development of granite crystal models with different fabrics," Geofluids, vol. 2021, Article ID 5533113, 15 pages, 2021.

[60] S. K. Singh, S. Raval, and B. Banerjee, "A robust approach to identify roof bolts in $3 \mathrm{D}$ point cloud data captured from a mobile laser scanner," International Journal of Mining Science and Technology, vol. 31, no. 2, pp. 303-312, 2021. 